\title{
Qualitative and quantitative evaluation of internal anal sphincter function in the newborn
}

\author{
V. E. BOSTON, S. CYWES, AND M. R. Q. DAVIES \\ From the Department of Paediatric Surgery, Red Cross War Memorial Children's Hospital, University of \\ Cape Town, South Africa
}

SUMMARY One-hundred-and-one normal neonates were examined manometrically in the first day of life to assess anorectal function. In order to overcome some of the difficulties in subjective interpretation of results, the stimuli used and the response pattern seen in the anal canal were measured. In the unstimulated state, all subjects demonstrated rhythmical changes in anal canal tone. Mean maximal intraluminal pressure in the anal canal decreased significantly after 10 hours of age and after the first meconium stool. Only five out of the 101 examined on the first day of life had an abnormal manometric response. It is significant that none of these had passed meconium at the time of examination, and that all had a normal response pattern at the age of 28 hours. In 20 of these babies the sensitivity of the rectoanal reflex was measured and found to be significantly increased on the third day of life compared with the first. The quantitative changes in anorectal reflex function in the newborn, are thought to be related to the state of physiological 'constipation' which exists in utero and in the early neonatal period. The results indicate that a normal response pattern can be obtained in healthy babies after the first day of life. Consequently, anorectal manometry will be meaningful as a diagnostic method thereafter in the neonatal period. Further, it is suggested that measurement of the stimulus and the response will add useful information and reduce subjective error in interpretation of results.

Confusion exists over the reported onset of normal anorectal function after delivery as measured by anorectal manometry. It has been suggested that this method of investigation will not be reliable in the early neonatal period and that in premature and/or low birth weight babies, this problem may be accentuated (Holschneider et al., 1976; Howard and Nixon, 1968). Conversely, other investigators have found no evidence to support this belief (Aaronson and Nixon, 1972; Suzuki et al., 1973; Verder et al., 1975; Boston and Scott, 1976).

A normal rectoanal reflex is said to be present when the internal anal sphincter is inhibited after rectal stimulation. This does not occur in Hirschsprung's disease (Lawson and Nixon, 1976; Howard and Nixon, 1968; Aaronson and Nixon, 1972; Suzuki et al, 1973; Verder et al., 1975; Boston and Scott, 1976; Holschneider et al., 1976).

Successful manometry depends upon a normal

Received for publication 28 April 1977 internal anal sphincter, as demonstrated by the presence of rhythmical changes in anal canal tone seen in the unstimulated state $(3-20 \mathrm{c} / \mathrm{min})$ (Kerremans, 1969; Boston and Scott, 1976; Hancock, 1976). There is no other practical method at present available for monitoring its activity. Therefore, if characteristic rhythmical changes in anal canal tone cannot be detected, interpretation of results will be spurious (Boston and Scott, 1976).

Clearly, if this method of assessment is to be of any value in neonatal diagnosis, otherwise normal babies should have a normal manometric response pattern at the same age as those who have been referred for investigation of anorectal dysfunction.

- The objects of this study were to establish, in the newborn period and in otherwise normal babies, firstly, whether the internal anal sphincter behaves in a similar way in the unstimulated state as it does in later life. Secondly, whether inhibition of the internal sphincter can be produced after rectal stimulation at this age, and, if not, when this can be expected to occur, and finally to assess the sensitivity of the rectoanal reflex during the first three days of life. 
Method

\section{ANORECTAL MANOMETRY}

All babies were investigated according to the method described by Boston and Scott (1976).

The pressure profile of the anal canal was determined, noting the presence of rhythmical activity and its characteristics, the functional anal canal length, and the point of maximal tone and intraluminal pressure.

Only when the anal canal was shown to be normal at rest was assessment of the rectoanal reflex attempted.

\section{MEASUREMENT OF RESPONSE}

In view of the subjective factor in interpretation of results it was decided to score the response pattern in each child (Table 1). It is accepted that the major criteria used are associated with normal function and were therefore given a heavier loading than the minor criteria. These are less important but are nonetheless useful in confirming the functional status of the anal canal.

The system was arbitrarily designed so that functionally normal subjects scored 8 or more points.

It was decided not to exceed a stimulus which generated a net intraluminal rectal pressure of greater than $10 \mathrm{kPa}$ and/or which caused radial expansion of the rectum by greater than $15 \mathrm{~mm}$.

\section{MEASUREMENT OF STIMULUS}

Measurement of the minimum stimulus required to elicit a response, in subjects who have a normal response pattern, will enable the sensitivity of the reflex to be assessed in absolute terms.

\section{PRINCIPLE}

The rectoanal stretch reflex complex, which anatomically is composed of a stretch receptor (as yet

Table 1 Rectoanal reflex, measurement of response

\begin{tabular}{lcl}
\hline Response pattern of anal canal & Normal & $\begin{array}{l}\text { Hirschsprung's } \\
\text { disease }\end{array}$ \\
\hline $\begin{array}{l}\text { Major criteria } \\
\text { Decrease in anal canal pressure of } \\
\text { greater than } 50 \% \text { for longer than } 10 \mathrm{~s}\end{array}$ & 4 & 0 \\
$\begin{array}{l}\text { Complete inhibition of rhythmical } \\
\text { activity in anal canal for longer than }\end{array}$ & 4 & 0 \\
$\begin{array}{l}\text { Ms } \\
\text { Minor criteria }\end{array}$ & \\
$\begin{array}{l}\text { Spontaneous inhibition of rhythmical } \\
\text { activity and/or decrease in anal canal } \\
\text { pressure greater than } 50 \% \text { for longer } \\
\text { than } 10 \mathrm{~s}\end{array}$ & 2 & \\
$\begin{array}{l}\text { Expulsion of catheter } \\
\text { Irregular type of anal canal rhyth- } \\
\text { mical activity with compound } \\
\text { wave form }\end{array}$ & 1 & 0 \\
$\quad$\begin{tabular}{l} 
Total \\
\hline
\end{tabular} & 12 & 0 \\
\hline
\end{tabular}

unidentified), a neural pathway, and the smooth muscle of the internal anal sphincter, behaves as one functional unit. It is an energy sensitive system and therefore the minimum energy input required to produce prolonged inhibition of the internal sphincter is a quantitative measure of the excitatory stimulus. This value, which will be referred to as the excitation energy, is inversely proportional to the sensitivity.

Prediction of the variables necessary to the calculation of the excitation energy is simplified if the balloon catheter which is used to elicit the response expands radially as a cylinder.

Then:

$$
\mathrm{E}=\int_{0}^{\mathrm{V}_{\mathrm{R}}} \Delta \mathrm{P} \mathrm{dV}
$$

Where $\mathrm{E}=$ Excitation energy.

$V_{R}=$ Minimum volume of the balloon at which the response occurred.

$\Delta \mathrm{P}=\Delta \mathrm{P}_{\mathrm{T}}-\Delta \mathrm{P}_{\mathrm{E}}$.

$\mathbf{P}_{\mathrm{T}}=$ Total pressure in the balloon in the rectum corrected for intra-abdominal pressure.

$\mathbf{P}_{\mathbf{E}}=$ Pressure at the same volume outside the subject.

The integral is nothing more than the area between the two curves demonstrated by the example in Fig. 1 . The excitation energy can be approximated numerically from these pressure volume curves. However, this calculation is time consuming and impractical for routine use.

Alternatively, if it is assumed that the compliance characteristics of the rectal wall are relatively constant, then measurement of the minimum tension generated in the rectal wall that is needed to elicit a response will be a measure of the excitation energy.

Again, using a balloon which expands radially as a cylinder, Laplace's law can be applied and:

$$
\mathbf{T}=\mathbf{P} \times \mathbf{R}
$$

Where: $T=$ Tension generated in the rectal wall.

$\mathbf{P}=$ Pressure exerted by the rectal wall on the balloon. $\left(\mathbf{P}_{\mathbf{T}}-\mathbf{P}_{\mathbf{E}}\right)$.

$\mathbf{R}=$ Radius of the balloon.

This provides a simple method of assessment suitable for clinical use. To test this philosophy the excitation energy and the tension in the rectal wall that are needed to elicit a response were measured and compared.

Fundamental to the calculation of both values is the fact that the balloon has not made circumferential contact with the rectal wall before inflation; thus the system has zero energy potential, and the energy input will be equal to the excitation energy.

Secondly, this method of expressing and comparing the sensitivity of the reflex is valid only when using a 


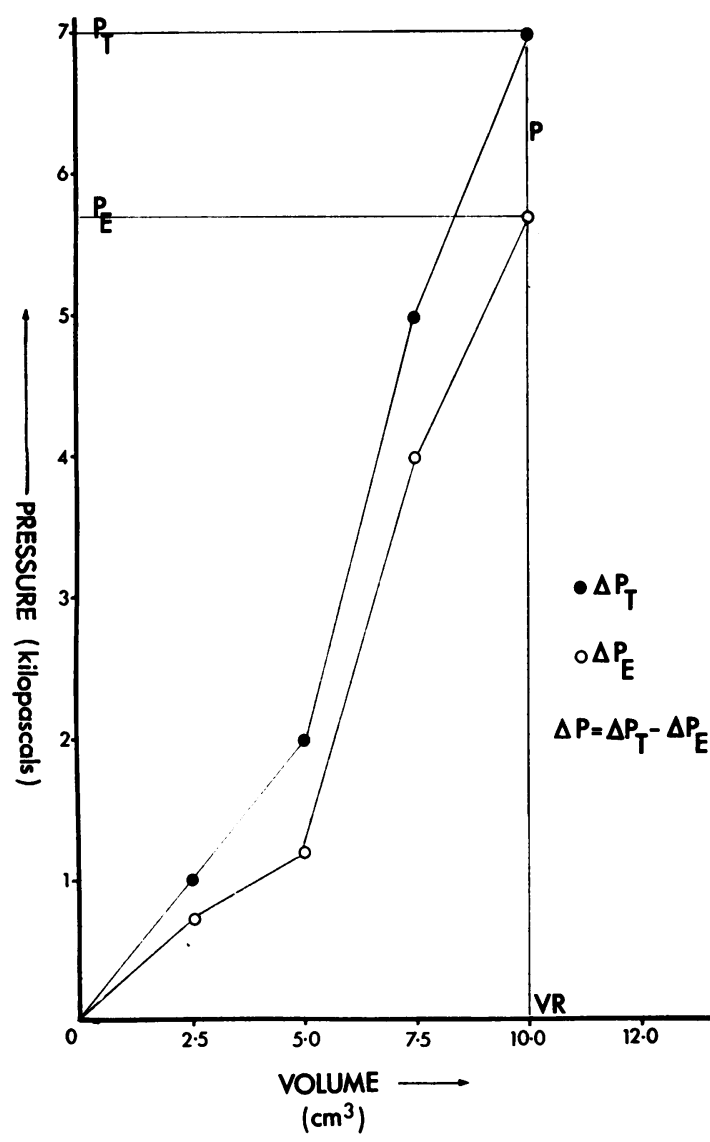

Fig. 1 Inflation curves showing volume/pressure relationship for the balloon inside and outside subject no. 18(a). From this can be calculated the excitation energy and the tension generated in the rectal wall required to elicit a response (see text).

standard balloon placed at a standard distance from the anal canal.

\section{TECHNIQUE}

A balloon catheter conforming to the expanding cylinder concept was designed and tested. This was shown to have the correct characteristics to within a maximum of $20 \%$ error even if axial deformation was $45^{\circ}$ (Fig. 2 and 3) However, this was valid only with inflation volumes of between 2.5 and $20 \mathrm{ml}$. Sterile saline was used as the inflation medium. Therefore, by determining the volume/radius characteristics of the balloon, it was possible to predict the radius at any inflation volume between 2.5 , and $20 \mathrm{ml}$. An example of the inflation data is shown in Fig. 1. The lower curve is obtained by inflating the balloon outside the subject at ambient atmospheric pressure. The upper curve is obtained by placing the balloon catheter in the anorectum, correcting for intraabdominal pressure, then inflating with increments of $2.5 \mathrm{ml}$ saline, and allowing for accommodation and stabilisation to occur before measuring $\mathbf{P}_{\mathbf{T}}$. The two curves will coincide for low volumes until there is circumferential contact between the balloon and the rectal wall.

With this data, the excitation energy and the tension generated in the rectal wall that is required to elicit a response can be calculated.

The intra-abdominal pressure was assumed to remain constant during the experiment and variations in atmospheric pressure were ignored as an important source of error.

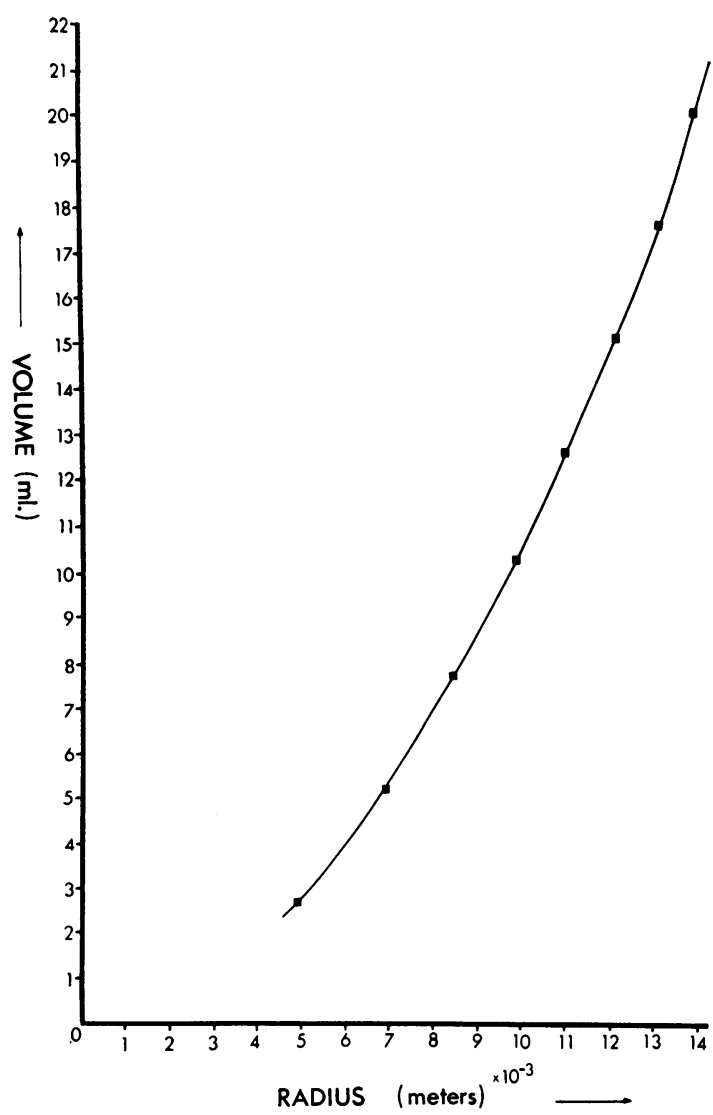

Fig. 2 The volume/radius characteristics of the balloon used to measure the stimulus. The effective length $(L)$ of the balloon calculated from the experimental data, using $V=\pi R^{2} L$, where $V$ is the volume and $R$ is the radius of the balloon at that volume, has a maximum error of $\pm 5 \%$. With axial distortion of the balloon to $45^{\circ}$ the error is $\pm 10 \%$. 


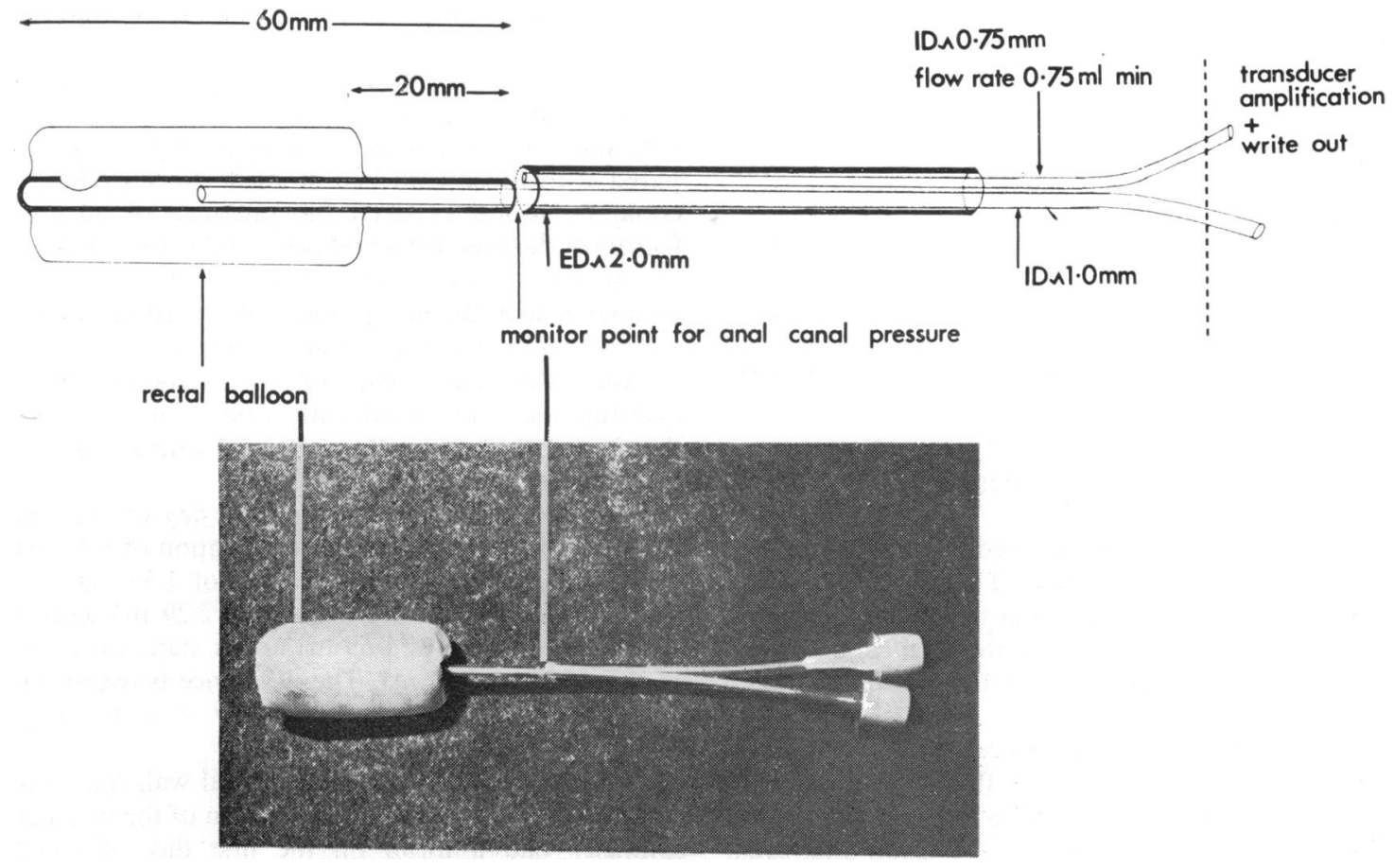

Fig. 3 Illustration of balloon used to measure stimulus

Lastly it was assumed that meconium, if present in the rectum, did not significantly alter the intraluminal geometry.

\section{SUBJECTS}

One hundred and one unselected newborn babies were examined in the first 28 hours of life. The time interval between delivery and examination was unselected, although an effort was made to investigate the subjects immediately after feeding. This was regarded as important only in as much as it ensured optimal observation conditions with the infant sleeping.

The response pattern score was recorded in each case. Any subject scoring less than 8 points was re-examined arbitrarily every few hours until the result fell to within a range previously defined as normal.

A further unselected group of 20 babies was examined on the first and third day after delivery and the mean tension and excitation energy required to elicit a normal response pattern score was determined.

Details were recorded in each case of the pregnancy, labour and delivery, sex, birth weight and gestational age, age at which the first meconium was passed, the feeding programme, temperature and weight at the time of examination, and general clinical details where relevant.

At follow-up patients were assumed to have normal anorectal function if they passed three or more well-formed stools per day, if they thrived normally, and had no significant abdominal distension.

Parental agreement was obtained for this investigation.

\section{Results}

The clinical details of 101 newborn babies are presented in Table 2. Eighty-two percent of the mothers received medication, usually a narcotic, within one hour before delivery. In those where delivery was by caesaréan section, atropine was given in addition. Forty-three percent of mothers had oxytocin either to hasten or induce labour and delivery.

All babies had an Apgar score of 8 points or more at 10 minutes after delivery and no subject had any significant complicating incident during the period of manometric assessment.

Technical difficulties made measurement of the functional length of the anal canal impossible to 
Table 2 Clinical data of newborn babies studied (101: male, 45; female, 56)

\begin{tabular}{lcc}
\hline & Mean & Range \\
\hline Gestational age (wk) & $39 \cdot 4$ & $33 \cdot 9-41 \cdot 2$ \\
Birth weight (kg) & $3 \cdot 17$ & $1 \cdot 74-4 \cdot 10$ \\
Delivery & No. & $\%$ \\
Normal after: & 74 & $74 \cdot 26$ \\
$\quad$ spontaneous onset of labour & 14 & $13 \cdot 86$ \\
$\quad$ induction of labour & 6 & $5 \cdot 94$ \\
Caesarean section & 6 & $5 \cdot 94$ \\
Elective for fetal distress & 101 & $100 \cdot 0$ \\
$\quad$ Total & & \\
\hline
\end{tabular}

within an error of less than $\pm 2.5 \mathrm{~mm}$. In the group as a whole, this length varied between approximately 10 to $15 \mathrm{~mm}$.

All subjects examined showed rhythmical activity in the functional anal canal. The character of this activity varied from individual to individual and, in addition, at different levels in the anal canal.

Ninety-two percent of the babies displayed an irregular type of rhythmical pattern where the dominant frequency was between 9 and $12 \mathrm{c} / \mathrm{min}$. Superimposed upon this were fluctuations in intraluminal pressure occurring at an estimated frequency of between 3 and $20 \mathrm{c} / \mathrm{min}$. In the distal anal canal at the point of maximal mean intraluminal pressure, this group frequently exhibited a dominant frequency of approximately $20 \mathrm{c} / \mathrm{min}$. However, the irregular nature of the pattern made it impossible to establish the frequency with accuracy. The majority of these cases had a low amplitude wave form. Ten percent of this group of babies had an ultra slow wave pattern which was apparent for short periods of time with a frequency of between 3 to $6 \mathrm{c} / \mathrm{min}$.

Eight percent of subjects displayed an obvious regular rhythmical pattern throughout the anal canal with a frequency of between 9 and $12 \mathrm{c} / \mathrm{min}$. These babies had a high amplitude wave form.

The mean maximal intraluminal pressure in the anal canal was observed to occur at approximately at $5 \mathrm{~mm}$ from the anal verge. This pressure had a range of 2.5 to $15.0 \mathrm{kPa}$ with a mean of $6.5 \mathrm{kPa}$. There wasa significant difference $(P<0.01)$ between the means of those who were less than 10 hours old compared with those who were older (7.13 and 5.9 $\mathrm{kPa}$ respectively). Similarly there was a significant difference $(P<0.02)$ between the means of those who had passed meconium at the time of investigation compared with those who had not $(6 \cdot 0$ and $6.9 \mathrm{kPa}$ respectively) (Fig. 4).

Five subjects had a response pattern score less than 8 points but all, when reinvestigated before 28 hours of age, scored within the defined normal range (Fig. 5). That these five babies had not passed meconium at the time of investigation is significant $(P=0.0194)$, compared with the group who had scored within the normal range.

There is no significant difference in the score obtained by those babies who had not passed meconium at the time of the first investigation compared with those who had stooled. No correlation could be found between the presence of adverse factors in the pre-, peri- and postnatal periods in that group of infants who had scored less than 8 points compared with the group that had scored normally.

The distribution with regard to age at assessment for the patients who had not passed meconium at investigation is not significantly different in the group that had scored normally compared with the group that had not (Fig. 5).

The excitation energy on the first day of life was 7.09 millijoules with a standard deviation of $6.13 \mathrm{~mJ}$ and a standard error of the mean of $1.37 \mathrm{~mJ}$. On the third day of life the mean was $2.29 \mathrm{~mJ}$ with a standard deviation of $1.69 \mathrm{~mJ}$ and a standard error of the mean of $0.38 \mathrm{~mJ}$. The difference between the means was statistically significant $(P<0.01)$ (Fig. 6).

The tension generated in the rectal wall that was required to elicit prolonged inhibition of the internal sphincter had a mean on the first day of 16.82 newtons $/ \mathrm{m}$ with a standard deviation of $14.26 \mathrm{~N} / \mathrm{m}$ and a standard error of the mean of $3.19 \mathrm{~N} / \mathrm{m}$. On the third day of life the mean was $6.82 \mathrm{~N} / \mathrm{m}$ with a standard deviation of $4.21 \mathrm{~N} / \mathrm{m}$ and a standard error of the mean of $0.94 \mathrm{~N} / \mathrm{m}$. The difference between the means was statistically significant $(P<0.01)$ (Fig. 7).

There were insufficient numbers to make the differences of the means statistically significant in those who had not passed meconium compared with those who had. The correlation coefficient of the excitation energy compared with the tension was 0.9077 , which is significant $(P<0.001)$.

There was no correlation between gestational age, birth weight, or any pre-, peri- and postnatal factors and the various wave forms observed in the anal canal. This also held true for the mean maximal intraluminal pressure readings in the anal canal and the sensitivity of the rectoanal reflex. All patients were assessed as having normal anorectal function at follow-up.

\section{Discussion}

CHARACTERISTICS OF UNSTIMULATED ANAL CANAL

All babies examined on the first day of life clearly demonstrated rhythmical changes in anal canal tone which were attributed to spontaneous activity of the smooth muscle sphincter. These children were 


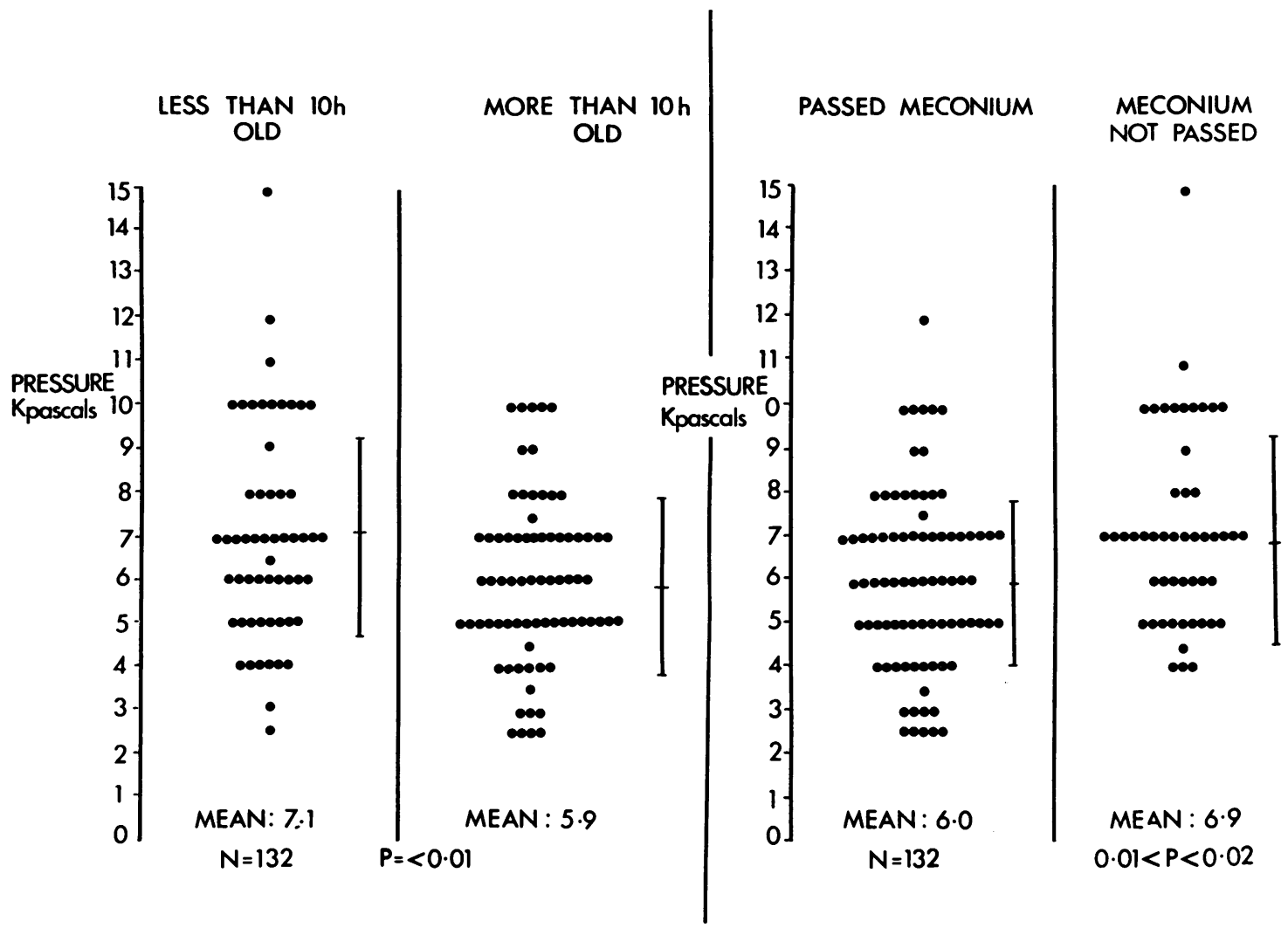

Fig. 4 Mean maximum intraluminal anal canal pressure

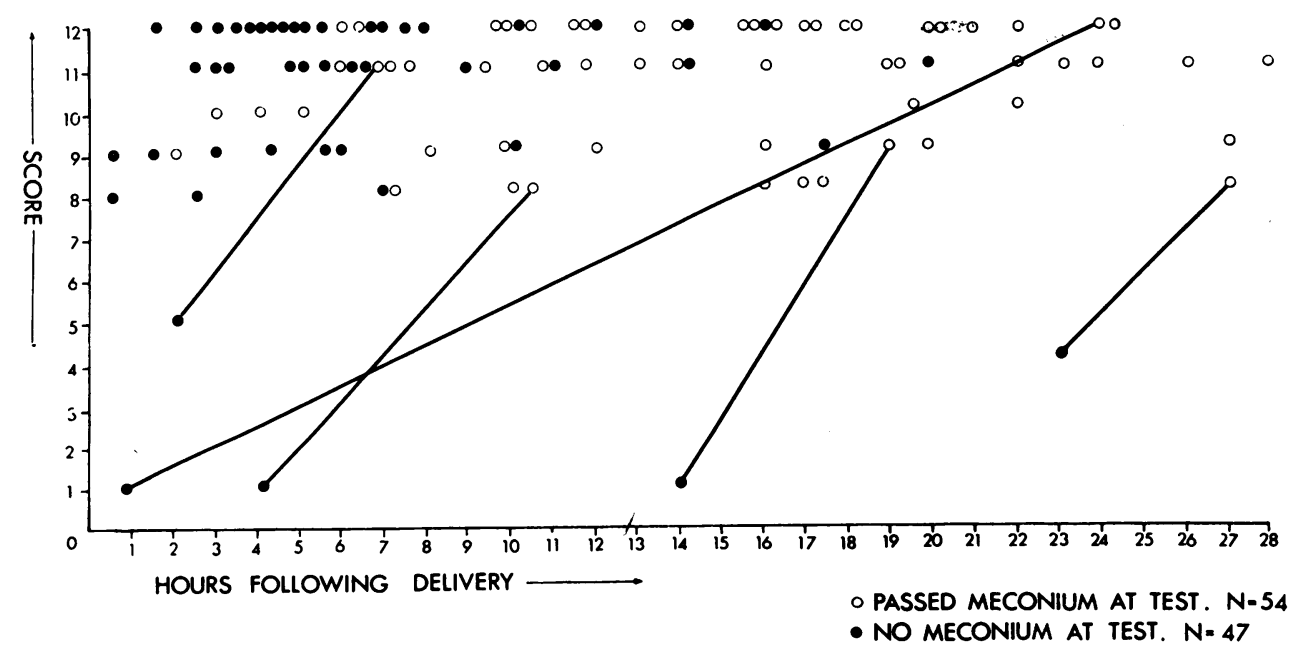

Fig. 5 Relationship between response score and age at investigation 


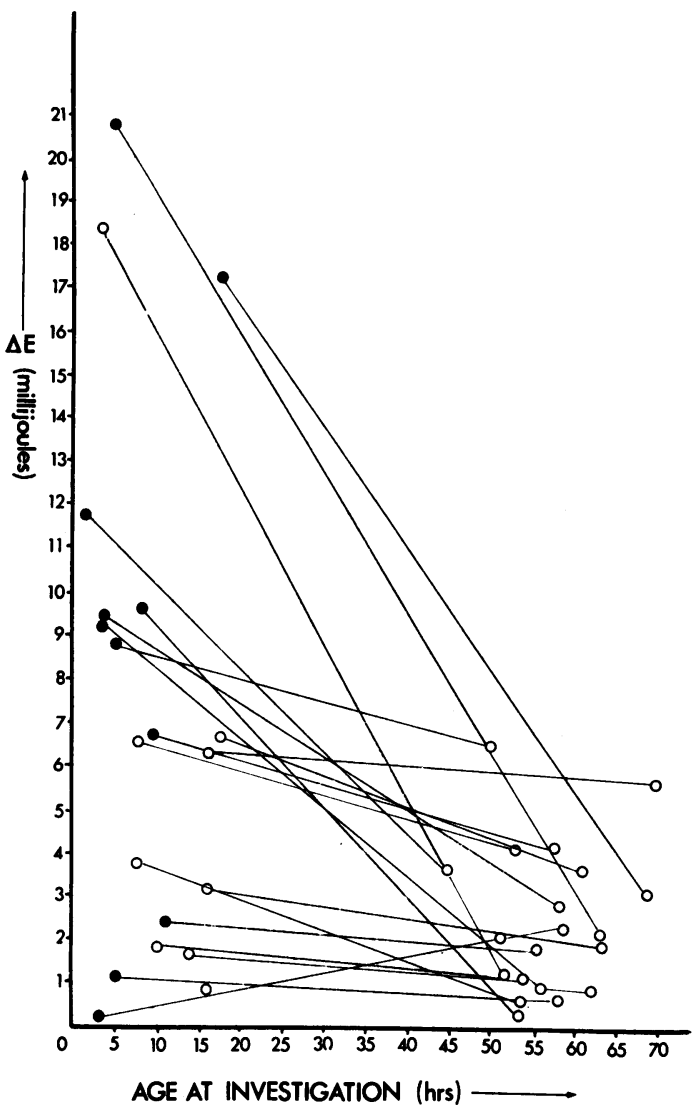

Fig. 6 Relationship between excitation energy required to elicit response and the age at investigation. The lines join the same subjects who were investigated on the first and third day of life. $N=20.0 .001<\mathrm{P}<0.01$.

- No meconium at test. $\bigcirc$ Passed meconium at test.

otherwise well. This observation is at variance with information from other centres where frequently newborn children did not display obvious rhythmical activity (Holschneider et al., 1976; Verder et al., 1976.) It has been established that systemic disease such as hypoxia, septicaemia, and/or hypothermia can cause a temporary cessation of spontaneous activity of the smooth muscle sphincter (Boston and Scott, 1976). This, however, was an infrequent observation. It is of interest that the irregular pattern noted in the majority of babies in this series was frequently associated with a wave form of low amplitude. It is suggested that, by using relatively insensitive equipment, it may not be possible to determine with certainty the presence of a rhythmical wave form of this type.

It has been suggested that mean maximal intra-

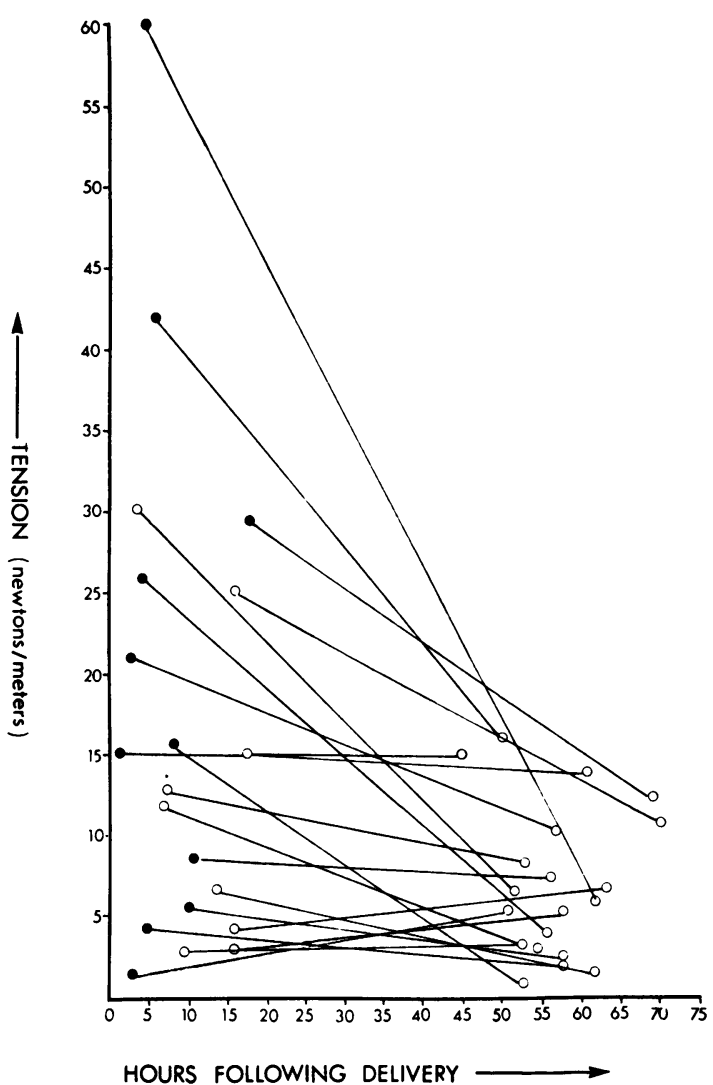

Fig. 7 Relationship between the tension generated in the rectal wall required to elicit a response and the age at investigation. The lines join the same subjects who were investigated on the first and third day of life. $N=20$. $T=3 \cdot 20549.0 \cdot 001<\mathrm{P}<0 \cdot 01$. No meconium at test. $\bigcirc$ Passed meconium at test.

luminal pressure in the anal canal increases with age after delivery (Holschneider et al., 1976). However, despite the wide variation at any given age in this series, there is a statistically significant decrease in anal canal tone after 10 hcurs of age. In addition, the mean maximal intraluminal pressure in the anal canal was significantly higher in those who had not passed meconium compared with those who had.

\section{RECTOANAL REFLEX}

On the first day of life an abnormal reflex pattern was obtained in only five subjects in this series. However, all babies were within normal range when re-examined before 28 hours of age. The remainder scored normally whether they had passed meconium or not at the time of examination. It is significant 
that all of the patients who scored below the normal range had not passed meconium.

It is tempting to postulate that because there is no significant increase in the response score with age (Fig. 5), the qualitative character of the recto-anal reflex is potentially normal regardless of age at the time of examination. Indeed, if any difference does exist it is in the degree of sensitivity only.

It had been reported that in only $39 \%$ of newborn babies with obvious rhythmical activity in the anal canal could a normal reflex pattern be induced (Holschenider et al., 1976). The use of an inadequate stimulus might be the explanation. This further supports the concept that there are differences in rectal sensitivity in the early neonatal period. However, it is possible that because of differences in interpretation a normal response pattern was not recognised.

\section{SENSITIVITY OF RECTOANAL REFLEX}

With this in mind measurement of the stimulus required to elicit a response and, hence, the sensitivity of the reflex was undertaken. The energy input into the system or the excitation energy, and the tension generated in the rectal wall that was required to elicit a response, were used as a means of measuring the stimulus.

The results clearly indicate that there is a significant increase in the sensitivity of the rectoanal reflex over the first three days of life. One might have expected that those patients who had not passed meconium at the time of examination would have been relatively insensitive. Unfortunately, there were insufficient numbers to confirm this statistically. This aspect warrants further study.

The tension generated in the rectal wall required to elicit a response correlated significantly with the excitation energy. Thus the tension, which is more practical for routine use, will be a satisfactory measure of the excitation energy and, hence, the sensitivity of the reflex.

There is no evidence in this series that prematurity per se influences the qualitative or quantitative response of the anal canal. However, it is admitted that insufficient numbers were investigated to make this conclusion statistically significant. It is felt that the matter requires further investigation.

The exact significance of these observations remains to be clarified but it could be postulated that it is relevant to the state of physiological 'constipation' which exists in utero and in the early neonatal period.

\section{Conclusion}

function in 101 otherwise normal newborn babies using anorectal manometry. All subjects clearly demonstrated rhythmical changes in the tone of the anal canal at rest.

Mean maximal pressure in the anal canal significantly decreases after the age of 10 hours and after the passage of meconium. In the first 28 hours of life only five babies had an abnormal pattern of response to rectal stimulation. The remainder were normal. It is significant that all these five subjects had not passed meconium at the time of investigation. All subjects had a normal response pattern at 28 hours of age.

The sensitivity of the rectoanal reflex was measured on the first and third days of life respectively in 20 of these neonates by measuring the stimulus. This was performed by measuring the excitation energy and the tension generated in the rectal wall that was required to elicit a response.

There was a significant increase in the sensitivity with age in the patients studied. The tension correlated significantly with the excitation energy and, as it is a more convenient measurement, it is recommended for routine clinical assessment of the stimulus.

It would appear that only the quantitative and not the qualitative functional characteristics of the anorectum are modified in the newborn period and this may bear some relationship to the state of physiological 'constipation' which exists in utero and in the early neonatal period.

There is no evidence to suggest that prematurity influences the results, although it is admitted that specific investigation of this question would be worthwhile with a larger series. The possible explanations for the confusion in the literature are discussed.

The results suggest that babies who are otherwise normal will have inhibition of the internal anal sphincter after adequate rectal stimulation after the first day of life and hence anorectal manometry should be a reliable diagnostic tool thereafter. It is suggested that measurement of the response pattern and the stimulus required to elicit a response may reduce subjective errors in interpretation.

The authors wish to thank Dr Vincent Harrison, of the Department of Paediatrics, University of Cape Town, for permission to examine his patients, Sister Vitals for assisting in data collection, and Dr Terry Van Der Werff of the Department of Bio-engineering, University of Cape Town, for his guidance in mathematical and biophysical problems.

\section{References}

Aaronson, I., and Nixon, H. H. (1972). A clinical evaluation 
of anorectal pressure studies in the diagnosis of Hirschsprung's disease. Gut, 13, 138-146.

Boston, V. E., and Scott, J. E. S. (1976). Anorectal manometry as a diagnostic method in the neonatal period. Journal of Pediatric Surgery, 11, 9-16.

Hancock, B. D. (1976). Measurement of anal pressure and motility. Gut, 17, 645-651.

Holschneider, A. M., Kellner, E., Streibl, P., and Sippell, W. G. (1976). The development of anorectal continence and the significance in the diagnosis of Hirschsprung's disease. Journal of Pediatric Surgery, 11, 151-156.

Howard, E. R., and Nixon, H. H. (1968). Internal anal sphincter: observations on development and mechanism of inhibitory respr- ses in premature infants and children with Hirschsprung's disease. Archives of Disease in Childhood, 43, 569-578.

Kerremans, R. (1969). Morphological and Physiological Aspects of Anal Continence and Defaecation, pp. 197-222. Arscia Vitgaven: Brussels.

Lawson, J. O. N., and Nixon, H. H. (1967). Anal canal pressures in the diagnosis of Hirschsprung's disease. Journal of Pediatric Surgery, 2, 544-552.

Suzuki, H., White, J. J., El Shafie, M., Shaker, I. J., Haller, J. A., Jr. and Schnaufer, L. (1973). Nonoperative diagnosis of Hirschsprung's disease in neonates. Pediatrics, 51, 188-191.

Verder, H., Krasilnikoff, P. A., and Scheibel, E. (1975). Anal Tonometry in the neonatal period in mature and premature children. Acta Paediatrica Scandinavica, 64, 592-596.

\section{The November 1977 Issue}

\section{THE NOVEMBER 1977 ISSUE CONTAINS THE FOLLOWING PAPERS}

Anatomy and radiology of the areae gastricae C. E. MACKINTOSH AND L. KREEL

Unstirred layer and kinetics of electrogenic glucose absorption in the human jejunum in situ N. W. READ, D. C. BARBER, R. J. LEVIN, AND C. D. HOLDSWORTH

Role of gastrointestinal hormones in the response to massive resection of the small bowel A. A. B. BARROS D'SA AND K. D. BUCHANAN

Increased tissue concentrations of 5-hydroxytryptamine in the duodenal mucosa of patients with coeliac disease D. N. CHALLACOMBE, P. D. DAWKINS, AND P. BAKER

Immunoglobulins in the jejunal mucosa in adult coeliac disease and dermatitis herpetiformis after the reintroduction of dietary gluten M. LANCASTERSMITH, SUSAN JOYCE, AND PARVEEN KUMAR

Nippostrongylus brasiliensis infection in the rat: effect of iron and protein deficiency and dexamethasone on the efficacy of benzimidazole anthelmintics V. M. DUNCOMBE, T. D. BOLIN, A. E. DAVIS, AND J. D. KELLY
Platelet function in fulminant hepatic failure and effect of charcoal haemoperfusion M. J. WESTON, P. G. LANGLEY, M. H. RUBIN, M. A. HANID, P. MELLON, AND ROGER WILLIAMS

Serum bile acids in the diagnosis of hepatobiliary disease C. R. PENNINGTON, P. E. ROSS, AND I. A. D. BOUCHIER

Association of abnormal fibrin polymerisation with severe liver disease G. GREEN, L. POLLER, JEAN M. THOMSON, AND I. W. DYMOCK

Inhibitory effect of various cytostatics and cycloheximide on acute experimental pancreatitis in rats L. KORBOVÁ, J. KOHOUT, F. MALIš, V. BALAS̆, J. ČIŽKOVÁ, J. MAREK, AND A. ČIHÁK

Technique Device for obtaining multiple simultaneous samples of intestinal contents during perfusion studies in man J. W. MATSESHE, J.-R. MALAGELADA, AND S. F. PHILLIPS

Progress report Intraepithelial lymphocytes of the small intestine ANNE FERGUSON

Notes and activities

Books

The British Society of Gastroenterology

Copies are still available and may be obtained from the PUBLISHING MANAGER, BRITISH MEDICAL ASSOCIATION, TAVISTOCK SQUARE, LONDON, WC1H 9JR, price $£ 2 \cdot 75$, including postage 